\title{
Interannual variability of winter precipitation in the European Alps: relations with the North Atlantic Oscillation.
}

\author{
E. Bartolini ${ }^{1}$, P. Claps ${ }^{1}$, and P. D’Odorico ${ }^{2}$ \\ ${ }^{1}$ Dipartimento di Idraulica, Trasporti e Infrastrutture Civili, Politecnico di Torino, Corso Duca degli Abruzzi 24, 10129 \\ Torino, Italy \\ ${ }^{2}$ Department of Environmental Sciences, University of Virginia, P.O. Box 400123, Charlottesville, VA 22903-4123, USA
}

Received: 30 June 2008 - Published in Hydrol. Earth Syst. Sci. Discuss.: 25 July 2008

Revised: 19 November 2008 - Accepted: 9 December 2008 - Published: 7 January 2009

\begin{abstract}
The European Alps rely on winter precipitation for various needs in terms of hydropower and other water uses. Major European rivers originate from the Alps and depend on winter precipitation and the consequent spring snow melt for their summer base flows. Understanding the fluctuations in winter rainfall in this region is crucially important to the study of changes in hydrologic regime in river basins, as well as to the management of their water resources. Despite the recognized relevance of winter precipitation to the water resources of the Alps and surrounding regions, the magnitude and mechanistic explanation of interannual precipitation variability in the Alpine region remains unclear and poorly investigated. Here we use gridded precipitation data from the CRU TS 1.2 to study the interannual variability of winter alpine precipitation. We found that the Alps are the region with the highest interannual variability in winter precipitation in Europe. This variability cannot be explained by large scale climate patterns such as the Arctic Oscillation (AO), North Atlantic Oscillation (NAO) or the East Atlantic/West Russia (EA/WR), even though regions below and above the Alps demonstrate connections with these patterns. Significant trends were detected only in small regions located in the Eastern part of the Alps.
\end{abstract}

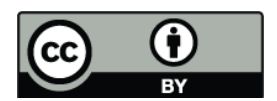

Correspondence to: E. Bartolini

(elisa.bartolini@polito.it)

\section{Introduction}

European Alps $\left(43^{\circ} \mathrm{N} \div 48^{\circ} \mathrm{N}, 5^{\circ} \mathrm{E} \div 17^{\circ} \mathrm{E}\right)$ are characterized by a complex climatology, due to the orography, the geographical location and the interactions with the weather systems which move eastwards from the Atlantic Ocean. The mountain chain stands at the crossroad of many different climatic systems (Polar, Atlantic, Saharian, Mediterranean and continental) and, because of its great altitudinal range, it exhibits a variety of climatic regimes comparable to that observed across widely separated latitudinal areas. The abundant water resources of the Alpine region are contributed both by rainfall and by snow, with the snow being a strategic seasonal storage of water that becomes available in the warm season, when snowmelt provides water both for agriculture and industrial uses. Because of the vulnerability of the Alps to climate change (Beniston et al., 1997) and the contribution of these mountains to aquifer recharge and to the base flow of the main European rivers, it is important to understand the patterns and drivers of seasonal and interannual changes in precipitation. This is especially true during the winter season, when most of the water storage accumulates in the snow pack. This study investigates fluctuations and trends in the interannual variability of precipitation and seeks for a relationship between monthly/seasonal precipitation and largescale patterns of atmospheric circulation. To this end, we assess the strength and areas of influence of possible climatic teleconnections and investigate the specific role that the Alps play in the European climatology.

Published by Copernicus Publications on behalf of the European Geosciences Union. 
In recent years a number of authors have investigated the patterns of interannual variability of precipitation in the Alps using different methods and obtaining results somehow constrasting. For example Quadrelli et al. (2001) investigate the winter precipitation variability for the period 19711992 and find significant relationship between rainfall and NAO; Beniston and Jungo (2002) detect clear links between strongly positive and negative modes of the NAO and extremes of moisture, temperature and pressure, especially for high elevation sites; Schmidli et al. (2002) detect only weak and highly intermittent correlations between winter alpine precipitation for the period 1901-1990 and the North Atlantic Oscillation Index. Not all these studies use spatially extended climatic records and in some cases only relatively short series are used (e.g., Quadrelli et al., 2001). Indeed, the use of long time series is crucially important to the analysis of climate trends and low-frequency modes of climate variability.

The modes of atmospheric circulation are recurring and persistent large-scale patterns of pressure and circulation anomalies that span vast geographical areas. These largescale patterns represent naturally occurring aspects of the chaotic atmospheric system and reflect large-scale changes in the atmospheric waves and jet streams, affecting the weather and climate of wide geographical regions (Hurrell and Van Loon, 1997; Thompson and Wallace, 2001). The modes of atmospheric variability considered in this study include the North Atlantic Oscillation (Hurrell, 1995), the Arctic Oscillation (Thompson and Wallace, 1998) and the East Atlantic West Russia (Barnston and Livezey, 1987). The North Atlantic Oscillation (NAO) is a large-scale pattern occurring in the atmospheric circulation of the North-Atlantic sector. The positive phase of the NAO is associated with anomalous high pressure in the subtropics and low pressure in the subarctic. This produces stronger westerly winds and enhanced flow of moist and warm air through the North Atlantic and Western Europe. Due to the stronger westerlies, winter precipitation is higher than average in the region between Scandinavia and Iceland and lower than average in Southern Europe. Winter temperatures are also affected by the NAO effect on the flow of cold arctic air across Western Greenland and the NorthWestern Atlantic and on the enhanced westerly flow of warm air over Europe. These conditions lead to relatively warm and rainy winters in Northern Europe (Hurrell, 1995). Opposite conditions occur during the low phase of the NAO. These phenomena are related to temperature fluctuations in Eurasia and to the strength of the stratospheric polar vortex, which are also associated with the patterns of the Arctic Oscillation (e.g., Thompson and Wallace, 1998, 2000) and the East Atlantic-West Russia pattern (Barnston and Livezey, 1987).

\section{Data}

The study of climate patterns in the relatively large and complex region of the European Alps requires the use of complete and long time series of spatially distributed monthly precipitation. To this end, a gridded dataset, constructed interpolating station records on a grid of given spatial resolution, is used. We have considered several databases (Global Air Temperature and Precipitation, NOAA- Center for Climatic Research Department of Geography University of Delaware, 2001; Analysis (Schmidli et al., 2001); HISTALP-ALP-IMP (Auer et al., 2005), and we have selected the monthly precipitation time series of the gridded database CRU TS 1.2 (Mitchell et al., 2003), developed by the Tyndall Centre for Climate Change Research and the Climate Research Unit (CRU) of the University of West Anglia. This data set provides the longest time series in the group and a good spatial resolution (grid spacing of about $20 \mathrm{~km}$ ). The dataset includes monthly time series of precipitation, temperature, vapour pressure, diurnal temperature range and cloud cover for all Europe $\left(34^{\circ} \div 72^{\circ} \mathrm{N}, 11^{\circ} \div 32^{\circ} \mathrm{E}\right)$ for the period 1901-2000. The dataset is constructed with the anomaly approach (New et al., 1999, 2000) interpolating station data with a procedure that considers latitude, longitude and elevation as parameters. However, the rain gauge records used for the interpolation in the CRU TS 1.2 data set are not corrected for rain gauge type, wind conditions or anthropogenic disturbances. This type of gridded dataset can be valuable in the study of spatio-temporal climate patterns in that it provides long and uninterrupted time series for all the grid points. The region of the European Alps, here considered as the region included in the rectangle having the corners specified in the introduction, is covered by a relatively dense network of rainfall stations. However, the spatial distribution of these stations is not homogeneous with respect to elevation and many of them have been added to the network only recently. Consequently, the interpolation procedure can induce some errors and biases in the gridded data, especially in areas with topographic singularities and low station density.

An extensive validation of the gridded time series is prevented by the lack of access to the original station data. However, a preliminary assessessment is made to check whether the gridded data can reproduce the major features of some time series recorded in rain gauges. To this end, and particularly to assess the ability of the dataset to capture the variability existing in the original precipitation records, we use data from nine meteorological stations to check the consistency between their rainfall records and those resulting in the grid cells respectively including the considered stations. The station data (Table 1) are taken from the archives of Regione Piemonte, Italy, and from the Global Historical Climatology Network of the National Climatic Data Center (National Oceanic and Atmospheric Administration, USA). The Pearson's correlation coefficient between the time series extracted from the gridded dataset and the station records is 
Table 1. Stations used for the comparison with the gridded dataset

\begin{tabular}{lcccccccc}
\hline Station & Lat $\left.^{\circ} \mathrm{N}\right)$ & Lon $\left({ }^{\circ} \mathrm{E}\right)$ & Elevation $(\mathrm{m}$ asl $)$ & Period of record & $\mathrm{r}^{*}$ & $\mathrm{~m}^{* *}$ & CV Station & CV cell \\
\hline Alessandria (IT) & 44.91 & 8.62 & 95 & $1901-1986$ & 0.821 & 1.334 & 0.889 & 0.818 \\
Dijon (FR) & 47.26 & 5.08 & 227 & $1831-2006$ & 0.997 & 1.096 & 0.591 & 0.575 \\
Domodossola (IT) & 46.11 & 8.29 & 252 & $1901-1996$ & 0.727 & 0.740 & 1.055 & 0.965 \\
Grenoble (FR) & 45.17 & 5.72 & 212 & $1845-1988$ & 0.883 & 0.961 & 0.628 & 0.596 \\
Klagenfurt (AU) & 46.65 & 14.32 & 459 & $1813-2006$ & 0.971 & 1.886 & 0.751 & 0.624 \\
Saentis (CH) & 47.25 & 9.35 & 2500 & $1883-2006$ & 0.920 & 0.380 & 0.666 & 0.695 \\
Sonnblick (AU) & 47.05 & 12.95 & 3109 & $1890-2006$ & 0.809 & 0.751 & 0.488 & 0.536 \\
Trento (IT) & 46.07 & 11.12 & 199 & $1861-1976$ & 0.964 & 1.143 & 0.945 & 1.267 \\
Zürich (CH) & 47.38 & 8.56 & 569 & $1836-2006$ & 0.973 & 0.918 & 0.587 & 0.609 \\
\hline
\end{tabular}

$*$ is the coefficient of correlation between the station and dataset time series

$* *$ is the slope of the constraint regression between station and gridded time series

used as an indicator of the consistency between gridded and station data. Scatterplots (Fig. 1) and constrained linear regressions are also used to assess the possible existence of a bias or an offset. While data from some stations demonstrate optimal agreement with grid data (Fig. 1a), in other cases, despite the strong correlation, the scatterplot deviates from the 1:1 line (Fig. 1b) demonstrating the existence of bias. In other stations the data roughly follow the 1:1 line, but with a weaker correlation (Fig. 1c) and a consistent bias (Table 1). In addition, a trend analysis is made for the corresponding grid and station records, showing that no significant trends exist for both the set of data, except for a weak discrepancy found in Trento and Sonnblick (see Bartolini (2007) for more details). Considering how the grid data are used in this paper, it is particularly important that the comparison between the annual and seasonal coefficients of variation of station and grid precipitation records comes out more than acceptable. This demonstrates that interannual variability of precipitation in the CRU TS 1.2 is comparable to that measured by the rainfall stations (Table 1) and confirms the good temporal agreement found by Bartolini (2007) between grid and station time series.

For the purpose of this investigation we quantify the temporal patterns of the North Atlantic Oscillation (NAO) through the NAO Index (NAOI), obtained from the Climate Research Unit of the University of West Anglia (Jones et al., 1997); the NAOI time series covers the 1821-2000 period and represents the normalized sea surface pressure difference between Iceland (Reykjavik) and Gibraltar. The Arctic Oscillation and the East Atlantic West Russia (Eurasian Pattern 2, Barnston and Livezey,1987) are quantified using indices available from the database of the NOAA, Climate Prediction Center. These indices are available for the period 1950-2000 and are calculated by applying the Rotated Principal Component Analysis (RPCA) to the monthly mean standardized $500-\mathrm{mb}$ geopotential height anomalies. In order to give an overall view of the connections between indices, their time

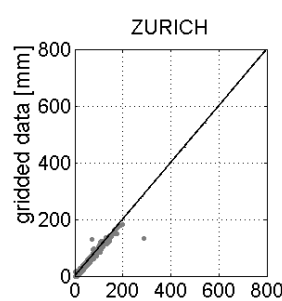

a)

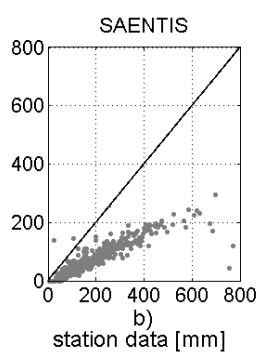

station data $[\mathrm{mm}]$

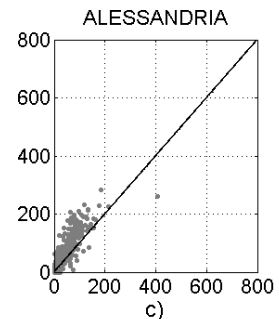

c)
Fig. 1. Representation of the agreement between monthly values of winter precipitation from the gridded and station data

series are shown in Fig. 2 and compared to the time series of the total winter precipitation anomaly averaged over the alpine region.

\section{Methods}

The spatial distribution of the interannual variability of precipitation is first evaluated in terms of coefficient of variation, calculated for each grid cell using the time series of the winter season (December-March) precipitation. The Standardized Precipitation Index (SPI, Mc Kee et al.,1993) is also used as a normalized indicator of the climate variability in the study area. This index is generally used as an indicator of drought conditions. However, it is in general a metric for the study of deviations from the mean, including wet anomalies. The SPI is the transformation of precipitation data, aggregated considering different time windows, into a normal distribution of standardized values. It is calculated as follows. Once a set of time windows is chosen, a new dataset is created aggregating with a moving sum the monthly precipitation. As precipitation is typically not normally distributed for aggregation windows smaller than one year (Mc Kee et al., 1993), a Gamma probability density function is fitted 

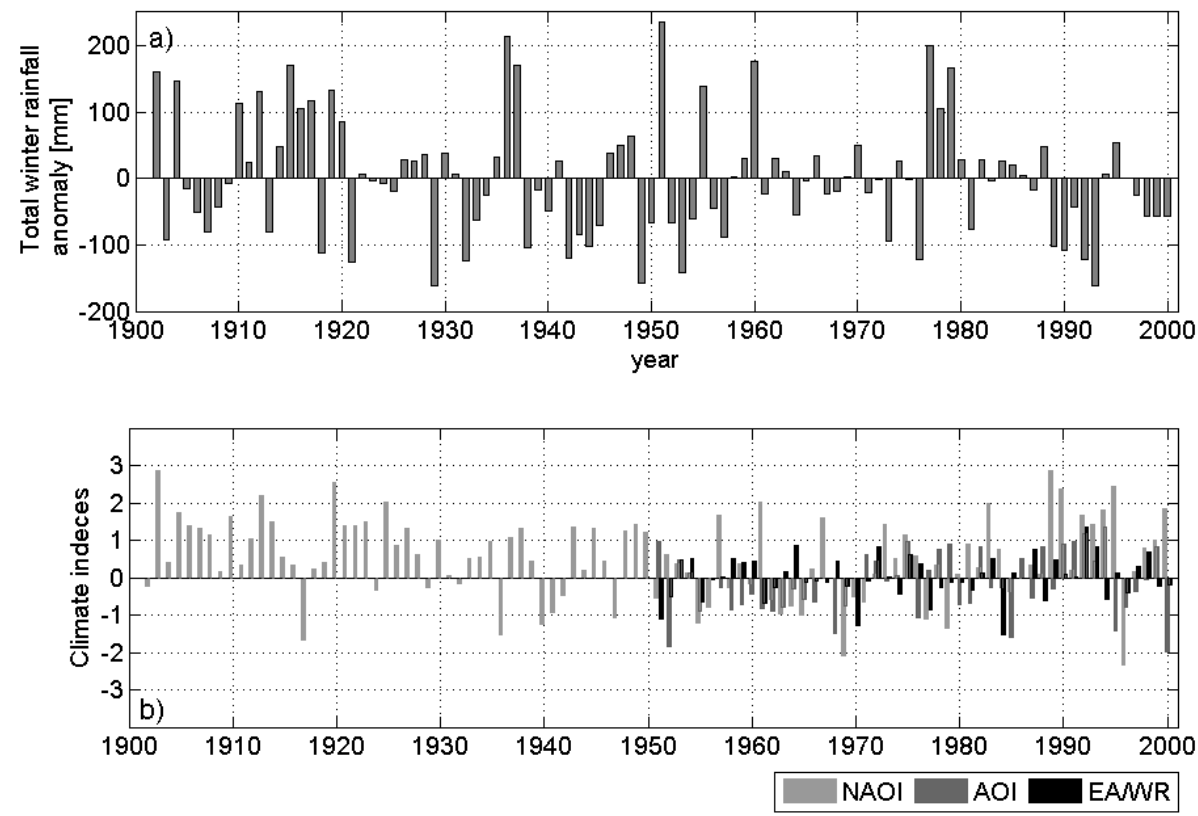

Fig. 2. (a) Time series of the winter total precipitation anomaly (December-March) averaged over the alpine domain; (b) Time series of the climate indeces used in the study

to the aggregated data. The resulting distribution is then transformed into a standardized normal variable $\mathrm{Z}$, i.e. with zero mean and unit variance, by means of an equiprobability tranformation. Therefore, for each precipitation value, the Gamma cumulative probability is mapped into a $\mathrm{Z}$ variable, which is the value of the SPI. The application of this procedure to the data, using the Anderson-Darling test, shows that the Gamma distribution fits the aggregated time series reasonably well: in fact, for the European Alps the Gamma passes the test with a significance level of 0.05 in the $67 \%$, $85 \%$ and $93 \%$ of cases respectively for 1,3 and 6 months aggregation time scale. The use of the SPI has some important advantages: first, it transforms the precipitation records into a standardized time series, thereby removing bias effects and allowing time series comparisons among stations with different mean and variance. Second, it can be calculated with different temporal scales of aggregation, that allows one to relate the index to events at the synoptic scale. Here we calculated the SPI for the winter season (JanuaryMarch) and for temporal intervals of the duration of 1, 3 and 6 months. In this way we obtain: (1) three SPI1, respectively SPI $1_{J}$ for January, SPI $1_{F}$ for February and SPI $1_{M}$ for March; (2) three SPI3: the SPI3 $J$ accounting for the precipitation from November to January, and, correspondingly, the $\mathrm{SPI}_{F}$ and the SPI3 ${ }_{M}$; (3) three SPI6, the $\mathrm{SPI}_{J}$ computed by summing the precipitation from August to January, and, correspondingly, the $\mathrm{SPI}_{F}$ and the $\mathrm{SPI}_{M}$. In addition, to investigate rainfall variability throughout the entire winter season, a modified SPI is determined using aggregation inter- vals starting in December and ending respectively in January, February and March. This choice is motivated by the fact that the NAO, AO and the EA/WR are known for their effect on winter European climate. Thus, we obtain the SPI IAN with the precipitation of December and January, the SPI $\mathrm{FEB}_{\mathrm{F}}$ with the precipitation from December through February and the $\mathrm{SPI}_{\mathrm{MAR}}$, that includes all the winter months (DecemberMarch). Incidentally, SPI $3_{F}$ and SPI $\mathrm{FEB}_{\text {coincide. Temporal }}$ trends in the precipitation and SPI time series are tested using the Mann-Kendall test with a 5\% significance level (e.g., Helsel and Hirsch, 1992), while the Spearman's Rank Correlation Test (e.g., Helsel and Hirsch, 1992) is used to evaluate the association between climate patterns and precipitation variability. This method is preferred to the Pearson correlation because it does not rely on any assumption about the probability distribution of the variables and it does not assume a linear relationship between them. The same test is carried out by removing from the time series the years presenting NAO close to "neutral", i.e., NAOI in the interval $(-1,1)$, to assess the effect of more extreme NAO phases on the precipitation variability. The results are shown in the next section.

\section{Results}

The map of the coefficient of variation (CV) of winter season precipitation across Europe is shown in Fig. 3, in which one can recognize that the Alps are a singular area of Europe, presenting, particularly in the Eastern sector, coefficients of 


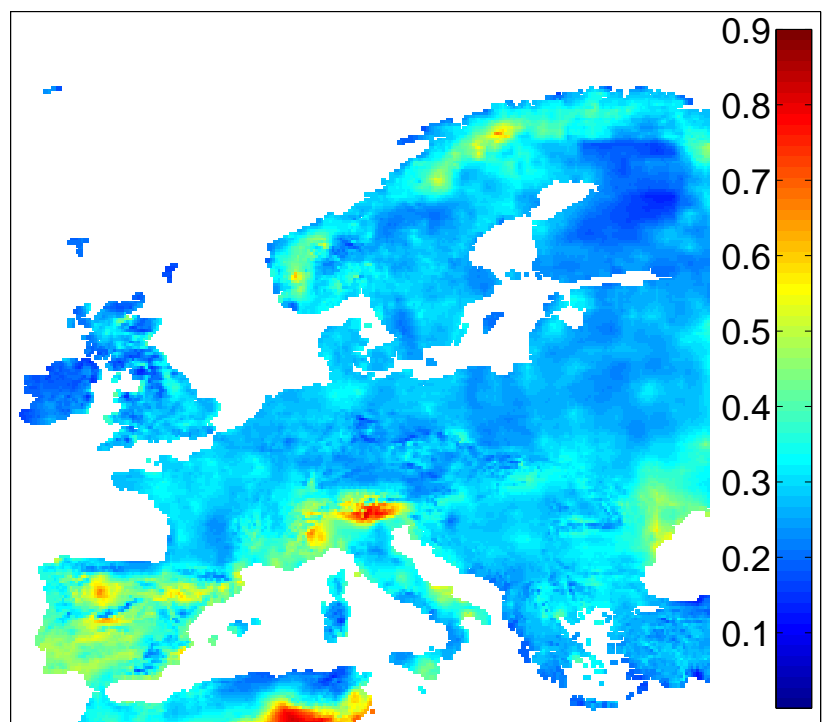

Fig. 3. Coefficient of variation of the winter precipitation (December-March).

variation of winter precipitation much higher than in the rest of the continent. Although mountainous areas are known for the relatively strong variability of their rainfall regimes, presumably due to orographic effects on local climate patterns, the relation between the interannual variability of precipitation and elevation remains unclear (Chacon and Fernandez, 1985). In fact, previous studies on the same data set (Bartolini, 2007) have shown that the relatively strong interannual variability observed in the Alps does not depend on the mean elevation of the grid cell or the mean winter precipitation. We have then investigated the influence of external forcings, such as the large-scale patterns of climate variability (NAO, AO, and EA/WR) on the climate of the alpine region, comparing monthly precipitation and SPI time series to indices representing the strength of these climate patterns. The Spearman's rank correlation coefficients (Fig. 4) calculated between NAOI and winter precipitation (JanuaryMarch) demonstrate that in the European Alps the dependence between winter precipitation and NAO is generally weak. In fact, it appears that the Alps are the European region in which the significance (i.e. p-values) of this relation is particularly low (Fig. 4b), with only a slightly higher significance on the Southern slope of the Alps, that would deserve furter investigation. Therefore, while the NAO is known to play an important role in determining climate variability in other areas of Europe, such as the Iberian Peninsula, Scandinavia, and the British Isles (Hurrell and Van Loon, 1997), no clear NAO signature can be found in the interannual fluctuations of precipitation in the Alps. The effect of the NAO on the European climate has opposite sign in Northern and Southern Europe: the NAOI is positively (negatively) cor-

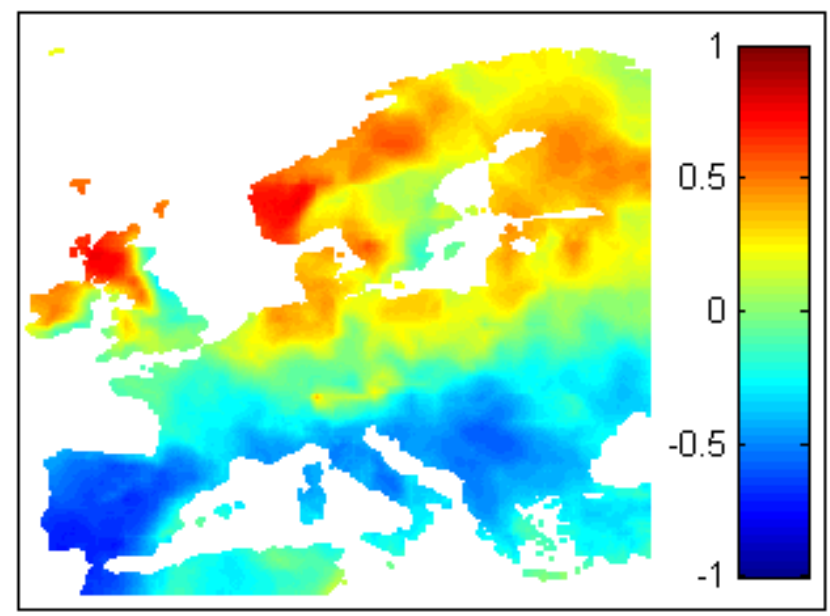

a)

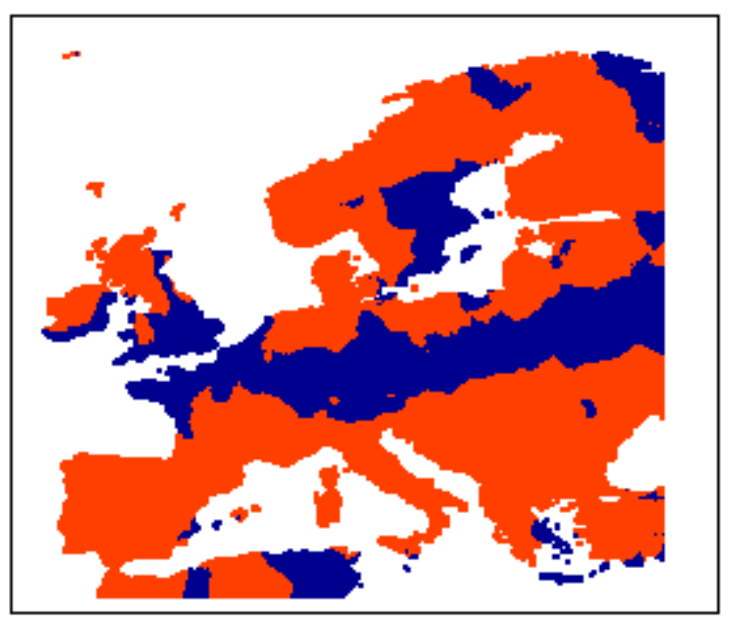

b)

Fig. 4. (a) Map of Spearman rank correlation coefficients between winter precipitation and North Atlantic Oscillation Index; (b) red areas represent regions where the correlation is significant.

related with winter precipitation in the Northern (Southern) part of the continent. The sign change occurs about at the latitude of the Alps (Fig. 4). Similarly, when compared to the rest of Europe, the Alps exhibit the weakest correlation between the NAOI and the Standardized Precipitation Index (SPI1, SPI3, SPI6 and modified SPI) as shown in Fig. 5 for the case of SPI MAR. To assess the influence of the extreme NAO phases on precipitation events, we have calculated the Spearman's rank correlation eliminating from the NAOI and SPI time series the years with NAOI values in the range $(-1,1)$. The spatial distribution of these correlation coefficients, that can be found in Bartolini (2007), exhibits 


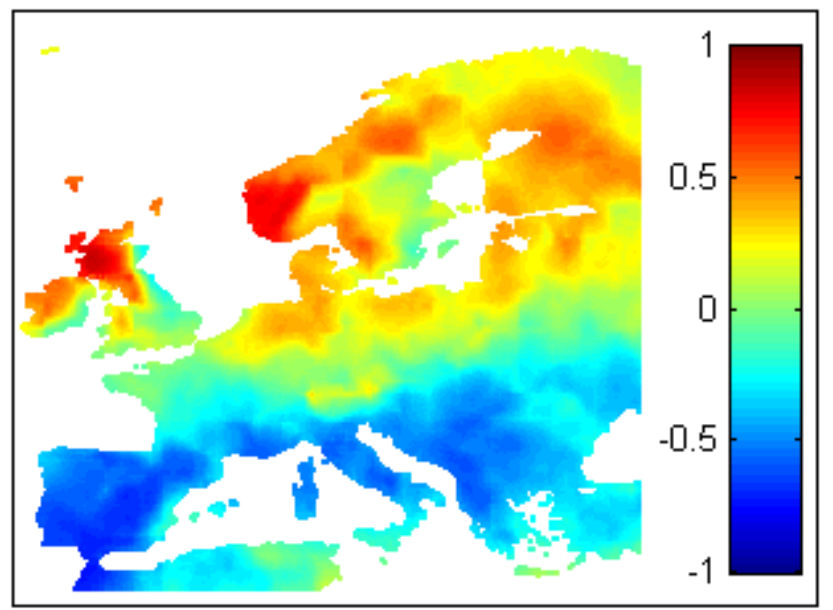

a)

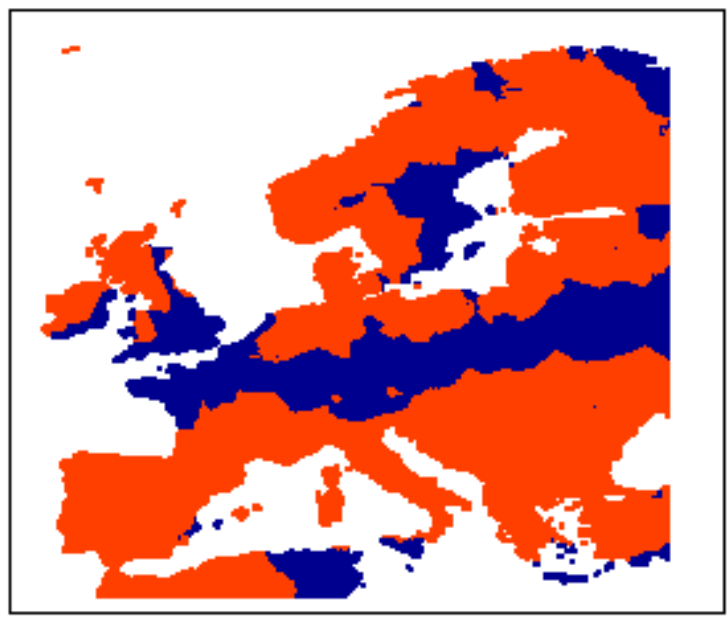

b)

Fig. 5. (a) Map of Spearman rank correlation coefficients between modified SPI MAR and North Atlantic Oscillation Index; (b) red areas represent regions where the correlation is significant.

patterns similar to those in Fig. 5 but with slightly higher values, demonstrating that the stronger phases of the NAO have a significant effect on the European climate, even though the result on the Alps does not change. Finally, we checked that introducing a lag between SPI and NAO would not significantly improve the results. After all these analyses we can conclude that the alpine region appears to be a transition region, with weak dependence on NAOI, and that the patterns of the North Atlantic Oscillation are unable to explain the strong interannual variability of precipitation observed in the Alps.

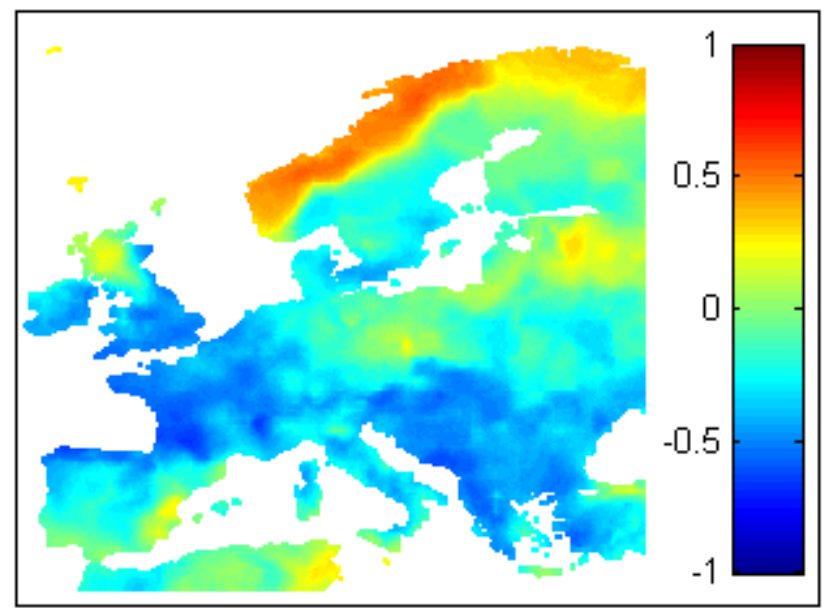

a)

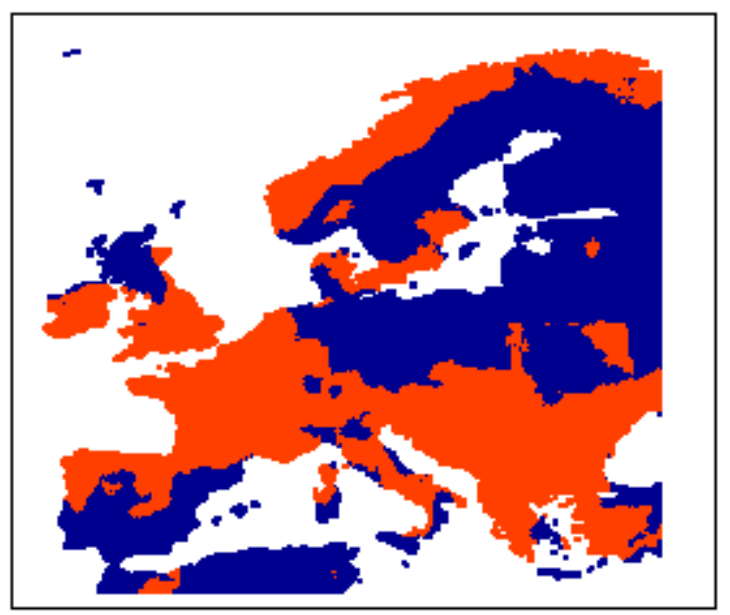

b)

Fig. 6. (a) Map of Spearman rank correlation coefficients between $\mathrm{SPI} 3_{F}$ and East Atlantic West Russia Index; (b) red areas represent regions where the correlation is significant.

The same statistical analyses used for the North Atlantic Oscillation are applied to assess the dependence of precipitation and of SPI on two other patterns of atmospheric circulation, the Arctic Oscillation (AO) and the East Atlantic West Russia. Not surprisingly, the AO has a similar impact on the regional precipitation as the NAO. The influence of the EA/WR is more interesting, in that the alpine region exhibits correlation coefficients that are mainly negative and significant (Fig. 6), particularly on the Northern and Eastern slope. However, this dependence does not persist throughout the winter season but it ends in February. 


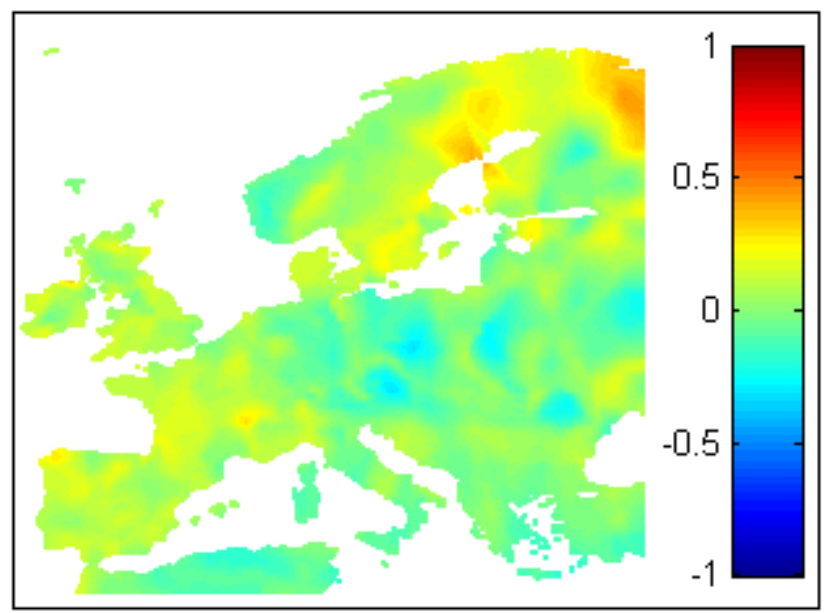

a)

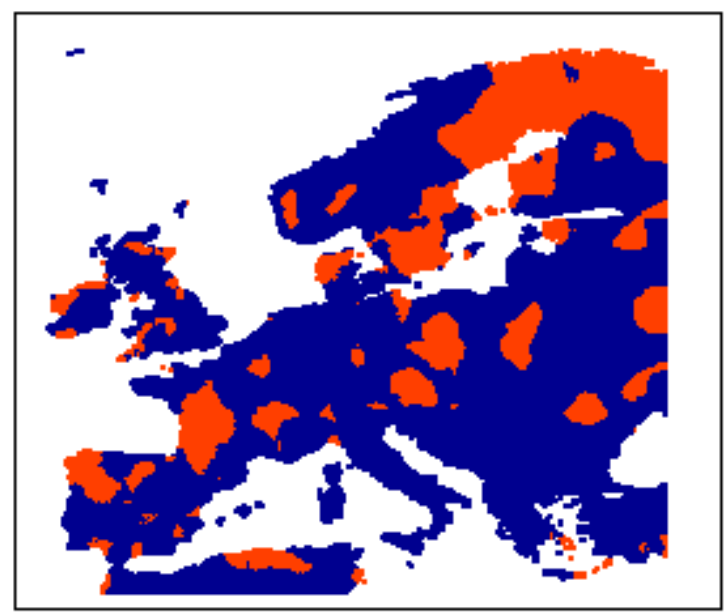

b)

Fig. 7. (a) Map of the Mann-Kendall trend coefficients for the winter precipitation; (b) red areas represent regions where a significant trend has been detected.

The presence of trend in winter precipitation time series is finally assessed using the Mann-Kendall Trend test. We identify two sub-regions: in the Western part of the Alps the trends are positive, while in the Eastern part they are negative. However, these trends are significant only in small areas (Fig. 7). These results contrast with those obtained by other authors (Haylock and Goodess, 2004; Quadrelli et al., 2001; Schmidli et al., 2002) who find trends in alpine precipitation over generally large areas. The differences can be presumably ascribed to the different length of the rainfall records and to the methods that are used. In fact Quadrelli et al. (2001) consider only the period 1971-1992; Schmidli et al.

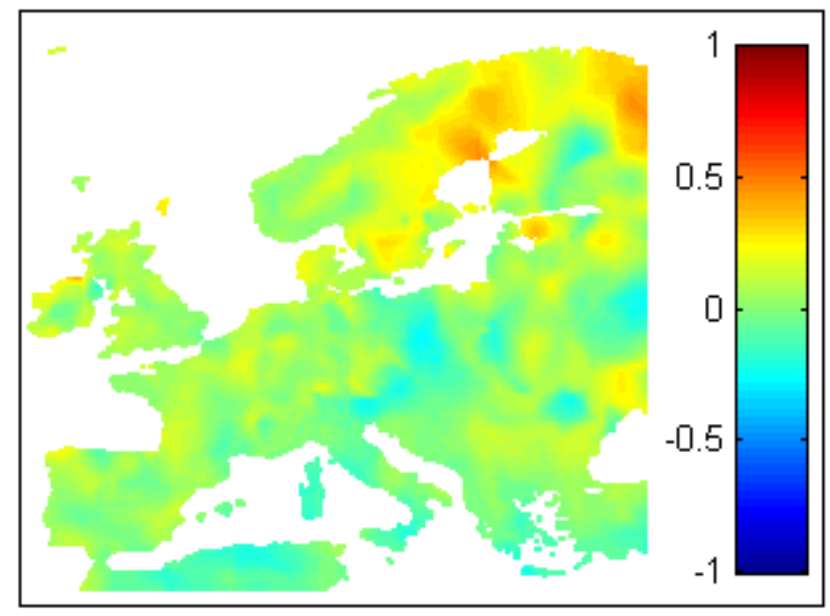

a)

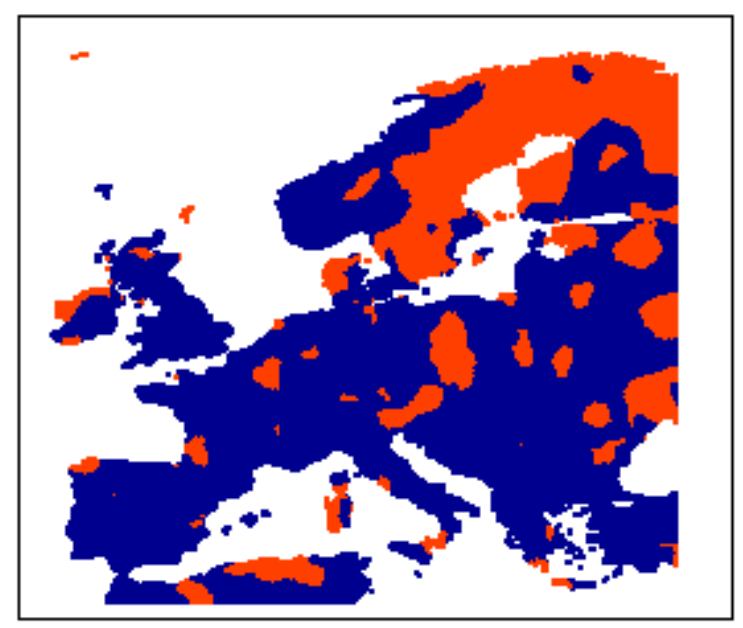

b)

Fig. 8. (a) Map of the Mann-Kendall trend coefficients for the mean winter SPI3; b) red areas represent regions where a signifcant trend has been detected.

(2002) calculate the trend as a fraction of the deviation from the climatological mean, while Haylock and Goodess (2004), concentrate only on extreme precipitation events. Our results show (Fig. 8) a significant and spatially coherent negative trend for SPI3 and SPI6 over the Eastern European Alps, indicating a decrease in precipitation and an increase in the occurrence of dry anomalies. 


\section{Discussion and conclusion}

In this study the interannual variability of winter alpine precipitation is investigated using the monthly precipitation time series obtained from the dataset CRU TS 1.2. This dataset was obtained by spatial interpolation and covers all Europe with a square grid having side of about $20 \mathrm{~km}$. A preliminary comparison between the precipitation time series in some rainfall stations and in the corresponding grid cells shows that the gridded data capture reasonably well the temporal variability observed in the station records, even with some bias and dispersion. Bias effects do not affect the rainfall variability, as represented by the coefficient of variation, and can be removed by considering Standardized Precipitation Index values.

The alpine region exhibits the strongest interannual variability of winter precipitation in Europe. In this paper an attempt is made to relate this variability to the dominant largescale modes of climate variability in the Northern Hemisphere. The Arctic Oscillation and the North Atlantic Oscillation are found to present only a weak correlation with winter alpine precipitation, regardless of aggregation scales, the use of time lags or the filtering of more extreme phases of the climate patterns. The East Atlantic-West Russia shows a significant negative correlation with precipitation anomalies but only for the first part of the winter season. Only some significant, yet small, trends are observed in a small region of the Alpine Eastern sector, that could suggest a small decrease in precipitation totals and an increase in short-term dry anomalies in this area (Fig. 7).

Overall, this study shows that the Alps are a rather singular climatic region in Europe, which exhibits precipitation regimes with two major distinctive features: 1) a particularly high interannual variability of winter precipitation, and 2) a weak dependence on the North Atlantic Oscillation and a slightly better association with the East Atlantic West Russia for the first part of the winter. The relatively strong variability of winter precipitation in the Alps seems to be endogenous to this region, possibly resulting by the complex interactions between climatic forcings and topography. Due to the importance of winter precipitation for the sustainability of alpine very diverse water uses that rely on snow accumulation and melting, the findings of this study deserve additional investigations. The challenge of dealing with uncertainties of rainfall measurements in mountains would make this research even more appealing.

Acknowledgements. The NAO Index has been calculated by et Jones et al., 1997 (available at the web page www.cru.uea.ac.uk/ cru/data/nao.htm). The AO and EA-WR indices were calculated by the Climate Prediction Centre (available online: ftp://ftp.cpc. ncep.noaa.gov/wd52dg/data/indices/tele_index.nh). The precipitation time series for the meteorological station have been provided by Regione Piemonte (CD source) and by the National Climate Data Center (available online at http://www.ncdc.noaa.gov/oa/climate/ ghen-monthly/index.php?name=precipitation). The dataset CRU
TS 1.2 is available online, subject to request to the autors, at the web page http://www.cru.uea.ac.uk/ timm/grid/CRU_TS_1_2.html.

Support from the Italian Ministry of Education (GRANT 2007HBTS85) is acknowledged.

Edited by: A. Montanari

\section{References}

Auer, I., Böhm, R., Jurković, A., Orlik, A., Potzmann, R., Schöner, W., Ungersböck, M., Brunetti, M., Nanni, T., Maugeri, M., Briffa, K., Jones, P., Efthymiadis, D., Mestre, O., Moisselin, J. M., Begert, M., Brazdil, R., Bochnicek, O., Cegnar, T., GajićČapka, M., Zaninović, K., Majstorović, Ž., Szalai, S., Szentimery, T., and Mercalli, L.: A new instrumental precipitation dataset for the Greater Alpine Region for the period 1800-2002, Int. J. Climatol., 25(2), 139-166, 2005.

Barnston, G. A. and Livezey, R. E.: Classification, seasonality and persistence of low-frequency atmospheric circulation patterns, Mon. Weather. Rev., 115, 1083-1126, 1987.

Bartolini, E.: Interannual variability of winter Alpine precipitation: relations with the North Atlantic Oscillation (in Italian), unpublished Master Thesis, Politecnico di Torino, Italy, 2007.

Beniston, M., Diaz, H. F., and Bradley, R. S.: Climatic Change at high elevation site: an overview, Climatic Change, 36, 233-251, 1997.

Beniston, M. and Jungo, P.: Shift in the distribution of pressure, temperature and moisture and changes in the typical weather patterns in the Alpine Regions in response to the behaviour of the North Atlantic Oscillation, Theor. Appl. Climatol., 71, 29-42, 2002.

Chacón, R. E. and Fernandez, W.: Temporal and spatial rainfall variability in the mountainous region of the reventazn river basin, Costa Rica, Int. J. Climatol., 5, 175-188, 1985.

Haylock, M. R. and Goodess, C. M.: Interannual variability of European extreme winter rainfall and links with mean large-scale circulation, Int. J. Climatol., 24, 759-776, 2004.

Helsel, D. R. and Hirsch, R. M.(eds): Statistical methods in water resources, Elsevier, Amsterdam, 1992.

Hurrell, J. W.: Decadal trends in the North Atlantic Oscillation and relationship to regional temperature and precipitation, Science, 269, 676-679, 1995.

Hurrell J. W. and Van Loon, H.: Decadal variation in climate associated with the North Atlantic Oscillation, Climatic Change, 36, 301-326, 1997.

Jones, P. D., Jãnsson, T., and Wheeler, D.: Extension to the North Atlantic Oscillation using early instrumental pressure observations from Gibraltar and South-West Iceland, Int. J. Climatol., 17, 1433-1450, 1997.

Lamb, P. J. and Peppler, R. A.: West Africa, edited by: Glantz, M. H., Katz, R. W., and Nicholls, N., in: Teleconnections linking the worldwide anomalies, Cambridge University Press, Cambridge, UK, 121-189, 1991.

Mc Kee, T. B., Doesken, N. J., and Kleist, J.: The relationship of drought frequency and duration to time scale, Eighth Conference on Applied Climatology, Anaheim, California, USA, 17-22 January 1993. 
Mitchell, T. D., Carter, T. R., Jones, P. D., Hulme, M., and New, M.: A comprehensive set of high-resolution grids of monthly climate for Europe and the globe: the observed record (1901-2000) and 16 scenarios (2001-2100), Working Paper 55, Tyndall Centre for Climate Change Research, Norwich, UK, 2003.

New, M. G., Hulme, M., and Jones, P. D.: Representing twentiethcentury space-time climate variability. Part I: Development of a 1961-90 mean monthly terrestrial climatology, J. Climate, 12, 829-856, 1999.

New, M. G., Hulme, M., and Jones, P. D.: Representing twentiethcentury space-time climate variability. Part II: Development of a 1901-96 monthly terrestrial climate fields, J. Climate, 13, 22172238, 2000.

Quadrelli, R., Lazzeri, M., Cacciamani, C., and Tibaldi, S.: Observed winter alpine precipitation variability and links with largescale circulation pattern, Climate Res., 17, 275-284, 2001.
Schmidli, J., Frei C., and Schär, C.: Reconstruction of mesoscale precipitation fields from sparse observations in complex terrain, J. Climate, 14, 3289-3306, 2001.

Schmidli, J., Schmutz, C., Frei, C., Wanner, H., and Schär, C.: Mesoscale precipitation variability in the region of the European Alps during the 20th century, Int. J. Climatol., 22, 1049-1074, 2002.

Thompson, D. W. J. and Wallace, J. M.: The Arctic Oscillation signature in the wintertime geopotential heigh and temperature fields, Geophys. Res. Lett., 29(9), 1297-1300, 1998.

Thompson, D. W. J. and Wallace, J. M.: Annular modes in the extratropical circulation. Part I and II , J. Climate, 13, 1000-1036, 2000.

Thompson, D. W. J. and Wallace, J.M.: Regional climate impacts of the Northern Hemisphere Annular Mode, Science, 293, 8589, 2001. 